\title{
Swirly: For Technology Supported Collaborative Pretend Play, Just Add Water
}

\author{
Larissa Nägele \\ University of Southern Denmark \\ Kolding DK 6000 \\ lanae16@student.sdu.dk
}

\author{
Randi Jessen \\ University of Southern Denmark \\ Kolding DK 6000 \\ rajes16@student.sdu.dk
}

\author{
Robb Mitchell \\ University of Southern Denmark \\ Kolding DK 6000 \\ robb@sdu.dk
}

\begin{abstract}
Pretend play is vital for fun and learning, but compared with other play types, appears underexplored by technology developers, particularly regarding multi-user toys. Playing with water offers rich full-bodied collaborative experiences, but very little interaction design has sought to exploit children's timeless fascination with water. This paper describes Swirly: a large multi-user splash controller designed to foster collaborative make-believe. Dynamic lighting on the internal surface of this wobble-able vessel responds to users manipulating the water contained. An initial user tests suggest great promise for combining electronics with water to foster active new social pretend play experiences. Based on this we offer several suggestions for designing digital-water social pretend play experiences.
\end{abstract}

Collaborative Play. Multi-user Interface. Pretend Play. Sensory Play. Shared Interface. Social Play. Water.

\section{INTRODUCTION}

Pretend play appears vital for the cognitive, emotional, and social development of toddlers (Berk, Mann and Ogan 2006, Paley 2009). However, parents and researchers have expressed concern that computer games and electronic toys impede children's abilities and interests in social games and full-bodied pretend play (Linn 2009, Plowman, Stephan and McPake 2010). Thus many researchers have called for technologies to foster creativity in open-ended play experiences (Bekker, Sturm and Eggen 2009, Cassell and Ryokie 2001).

Playing with substances like water and sand are often held up as necessary healthy counterpoints to digital play experiences. The rich sensory stimulation that comes from manipulating these rather ephemeral materials are widely argued to bring many development benefits (Gascoyne [ ]. Water is ubiquitous in many parts of the world, and such plentifulness combined with its unpredictability means water play is frequently very social. Moreover, many children very much enjoy playing with water. The simplicity of these materials in the hands of children can heighten the opportunity for imagination and pretend play. The act of mixing materials and crafting imaginative landscapes can easily lead to an open-ended play experience that many different children can embrace. As David Howes describes:

"Water is a sensory extravaganza, as children feel the wetness, hear the splashes and sprinkles, see the bubbles and waves and maybe even taste a few droplets." (2004:47).

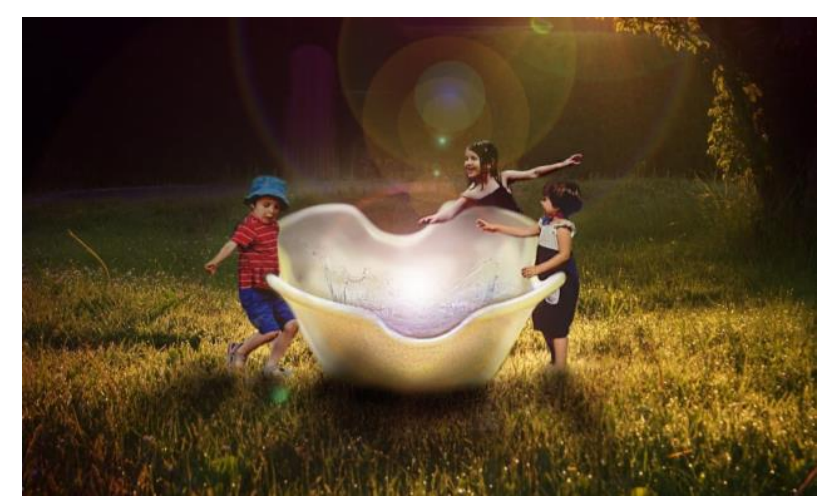

Figure 1. Envisioned collaborative pretend play

The ephemerality of these simple play materials means that they embed elements of surprise and temporality as well as a sensory experience.This paper proposes a design to explore how a multiuser interface may combine the attractive richness of water play and interactive lighting in order to provoke collaborative pretend play experiences (figure 1 and 2).

\section{RELATED WORK}

How water play easily lends itself to social experiences is exemplified by the interactive fountains of "Water Games" (Parés, Durany and Carreras 2005). This outdoor installation, tracked the movement of visitors, activating water jets when people held hands to form a "ring" and move together around a fountain. This seminal work, however, requires a lengthy setup and does not 

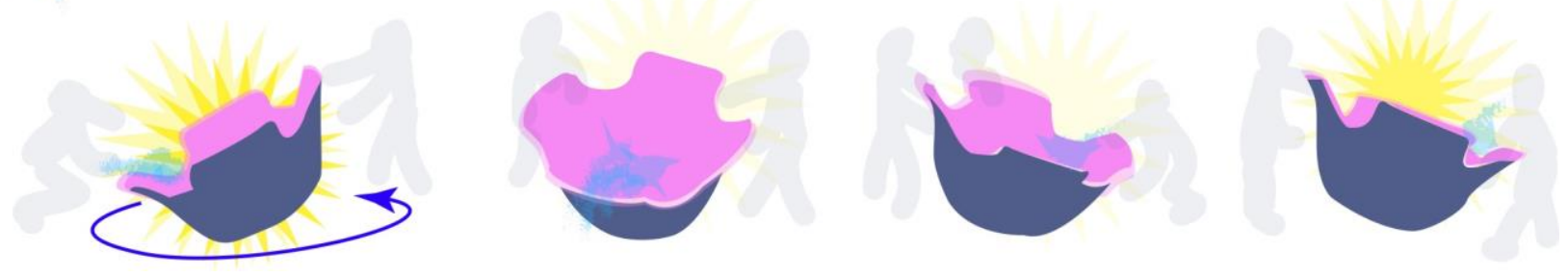

Figure 3. Interaction Sketch for the Swirly concept showing scale in relation to target users

foster much direct manipulation of water itself. T.U. Eindhoven researchers report success in nurturing open-ended social play by adding interactive lighting to play objects such as tubes (Bekker Sturm and Eggen 2009) and floor tiles (Valk, Bekker and Eggen). However, these examples also do not directly involve the rich sensory stimulation enabled by interaction with ephemeral materials. More recently, Raffe et al. (2005) offered useful taxonomies for aquatic interaction design, but they discuss mainly sports-like activities as they acknowledge that there is a limited pool of playful digital water-play examples. We take inspiration from Guerts and Abeele's "Splash Controller" concept of interfacing with computers via manipulating liquids in a receptacle (2012). They demonstrate how a water-filled bowl can be a game controller but we have not yet seen any attempts to use this technology to provoke collaborative pretend play for young children.

\section{INTRODUCING SWIRLY}

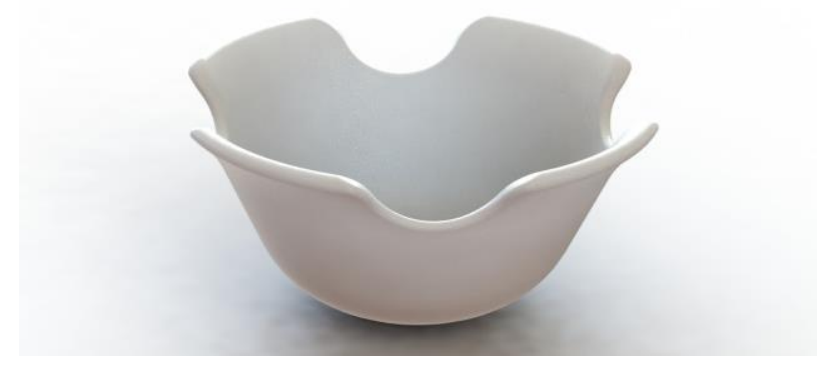

Figure 3.1 CAD model of Swirly for building

Our prototype takes its name from the adjective describing how the twisting and churning movements of water triggers its dynamic lighting effects (Figure 3). Swirly was inspired by reflecting upon our most cherished childhood experiences at the beach. Like many children, we had a fascination with ephemeral materials, such as water and sand that we could manipulate and create with. Most of all we enjoyed their sensory qualities and unique malleability, that helped us create our own play scenarios.

\subsection{Physical form to foster shared engagement}

Swirly is a plastic vessel in the form of cone with undulating edges so that it loosely resembles an seashell, or a four petal flower (figure 3.1). We intended the curved indentations in its rim to provide grip points for different users of heights, and to enable smaller children to look inside. It is $60 \mathrm{~cm}$ tall and at its widest point, its rim measures approximately 1.1 meters in diameter. We hoped this large scale would foster embodied social experience and invite physical collaboration. Swirly is much narrower at its base. The base is rounded so that the entire structure can wobble in response to being touched, but not so much that it completely tips over. Our hope was that the form itself and the simple mechanical interaction of its teetering can attract children to look inside the water vessel and interact further.

\subsection{Technology}

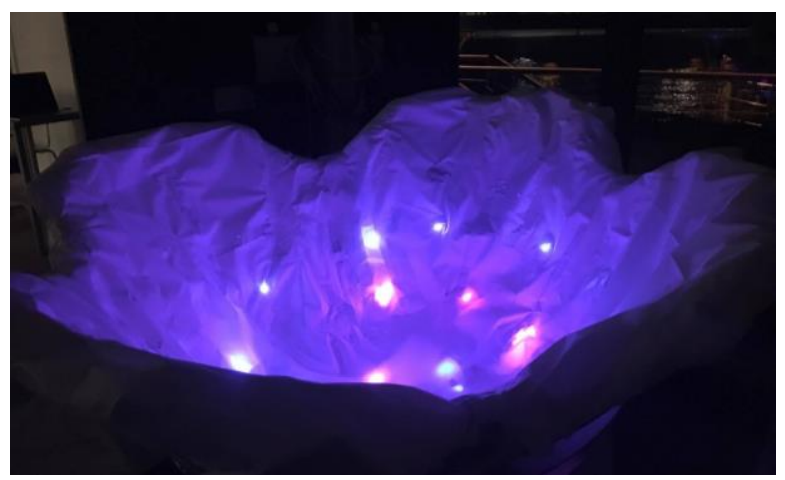

Figure 3.2. Experimenting with Swirly in a dim-lit context

The inner surface of the bowl is lined with transparent plastic. Underneath this waterproof layer, we embedded 16 programmable RGB LEDs (figure $X X$ ). The dynamic LEDs were evenly spread out across the inside of the bowl proper, but not in the "handle" like protrusions. Discretely nestled on top of the waterproof layer were three dotted lines of wire that formed three rings across different heights of the bowl. These rings of wire were connected to an Arduino micro-controller concealed in the base of the vessel. 
Similar to the Splash Controller (Guerts and Abelee 2012) the rings function as contact points of what is ordinarily an open circuit. However, adding water to Swirly creates possibilities to close the circuits in different way and trigger four different lighting effects:

(i) As the water hits the first level the lights are only a dimly lit and a pale purple-ish blue colour.

(ii) When the water connects the first and second levels the brightness increases, and the colours change to a warmer purple and pink (see figure 4 and 6)

(iii) When water is splashed high enough to be in contact with only the third level, Swirly lights up bright red.

(iv) If the water connects all three levels of ring simultaneously, this triggers a multi-colour "rainbow" effect at maximum brightness.

We intended for the interactivity to not only provide individual intrigue, but also stimulate collaborative pretend play. Mappings between the water and the circuit contact points at different levels is an attempt to rewards more physical actions, which in turn may provoke more imagination response. We deliberately designed Swirly to have a narrativefree form, so that it is open for interpretation by children's imagination. For example, children might interpret Swirly as a witches' cauldron, a scientific experiment, a giant machine, or a small pond or puddle. Accordingly the rising water level turning red could be seen as variously as a warning of danger, an angry mood, a temperature indicator, a sunset, or a raspberry flavour etc.

\section{INITIAL PLAYTEST WITH CHILDREN}

A group of three boys and three girls, aged 3-5 years and attending the same local kindergarten tested Swirly whilst visiting our studios, accompanied by their pedagogues. We placed the artifact on the concrete floor in the middle of our workshop. As children watched from several meters away, we poured water into Swirly to "activate" its abilities. Pouring in water in itself caused the bowl to wobble slightly. We then invited the children to play, as we retreated to the edge of the room and proceeded to video record the test.

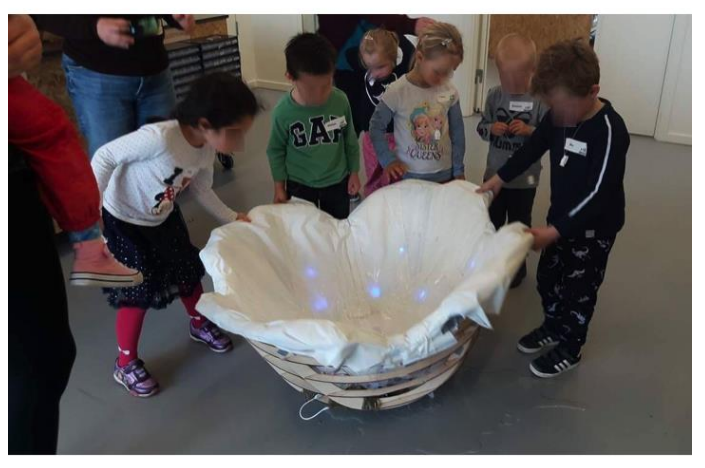

Figure 4: Children explore the rocking and illuminations of our splash controller

\subsection{Observations}

This initial test was too brief and closely monitored to investigate if Swirly could foster pretend play. However, we gleaned the following insights concerning how children engaged with the design.

The children shuffled around the sides of Swirly to grab the ledges that dip down, allowing them to see inside the bowl. As soon as one of the children teetered Swirly, the children on the opposite side reacted and pushed back. Swirly began to tip and swirl allowing the children to interact playfully as the water inside the vessel swished and propelled the form. Aside from the children's interest in pushing the form back and forth, they curiously gazed at the flashing lights and varying colours produced by the splashing water. Initially, their actions were rather gentle. After we explained that "if you push the bowl more, more colours show up" they became more daring and vigorous. When the LEDs glowed red, the children were alarmed and looked up at us with a mixture of bewilderment and excitement. The pedagogues and children knew they were being daring when the red showed up based on their "oohs", nervous laughter and looks.

When the children gathered around this bowl they formed a collective circle that allows a team effort in creating "something" depending on the pretend play scenario. The testing also reveals the children's initial intrigue into the scale of the object as this also invited them to "physically" engage. Lastly, the water as initially hoped, created a universal play experience that helped bring the children together collaboratively.

Due to the test context, the children were not able to completely emerge themselves in the play experience that Swirly affords. The supervising pedagogues were wary of letting the children completely engage with Swirly because this may have resulted in water-covered clothing. 


\section{FURTHER WORK}

We also have created a number of physical props as accessories to increase possibilities for interacting and scaffold imagination in different ways. These props are a mixture of water vessels, solid shapes and absorbent materials. Some of these artefacts such as the giant spoon allow for indirect manipulation of the water. This may also reduce the chances that children's clothes become soaked through interacting with Swirly. Internal tests with adults from the toy industry and academia have been encouraging but we look forward to discovering how children respond to, and with them.

We propose that these props can also have play themes associated with them (see figure XX). We believe this could help foster a diversity of pretend play experience.
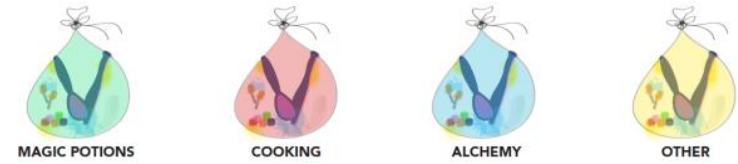

Figure 5: Tangible props in various themes.

We are also excited at the prospect of offering several different splash controllers to groups of children to play at the same time. This may help give a richer perspective of if, and how children prefer to collaborate with such artefacts (see figure 5.1 for an optimistic vision).

\subsection{Future testing}

Based on our informal trial, important aspects for further attention include, contextual setting, duration, and more discrete forms of supervision and observation so that children play more naturally. We also need to test in a context in which water play is not considered problematic due to risks of people or property becoming drenched. Testing under various lighting conditions will also help us understand the impact of the LEDs behaviour on children's experiences.

We noted the initial testing with the children proved how important context is for Swirly. Pretend play can better succeed when an adult is not supervising, therefore a situation where swirly is left in the hands of the children could help push the experiences that Swirly affords. Moreover, the LEDs in Swirly were not fully utilised to their potential since the test was conducted in a very bright room. In a dimly lit setting, Swirly's LEDs are more noticeable and would thus create more imaginative scenarios.

\section{CONCLUSION}

We have presented Swirly, a large multi-user splash controller designed to foster collaborative pretend play. Initial results indicate that the form and interactivity create engaging shared experiences. We look forward to further testing and iteration to explore the potential for combining liquids and digital interactivity for the fun and learning of young children.

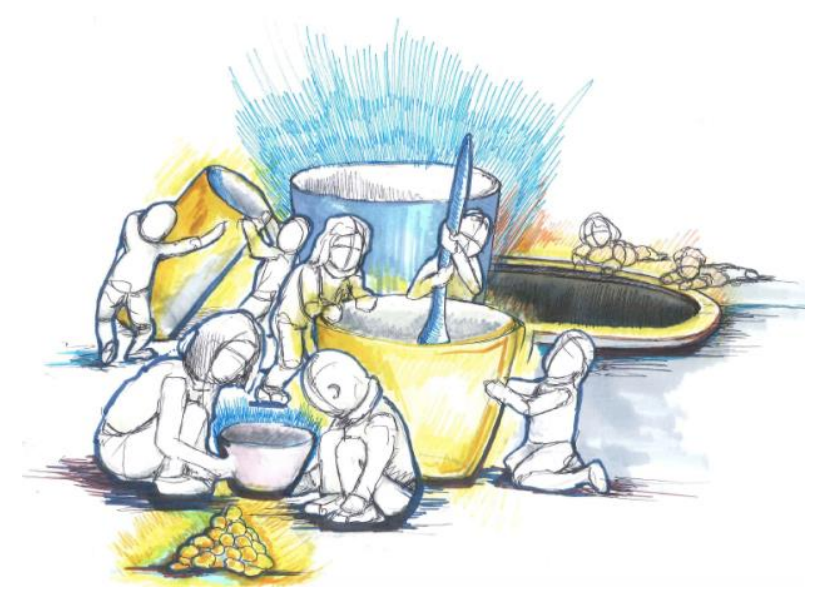

Figure 5.1: Swirly collaborative pretend play scenario

\section{REFERENCES}

Bekker, T., Sturm, J., Eggen, B., 2010. Designing playful interactions for social interaction and physical play. Personal and Ubiquitous Computing 14, 385-396.

Berk, L.E., Mann, T.D., Ogan, A.T., 2006. Makebelieve play: Wellspring for development of selfregulation. Play= learning: How play motivates and enhances children's cognitive and socialemotional growth 74-100.

Cassell, J., Ryokai, K., 2001. Making Space for Voice: Technologies to Support Children's Fantasy and Storytelling. Personal Ub Comp 5, 169-190. https://doi.org/10.1007/PL00000018

Gainsley, S., 2011. Look, Listen, Touch, Feel, Taste: The Importance of Sensory Play 12.

Gascoyne, S., 2016. Sensory play: Play in the EYFS. Andrews UK Limited.

Geurts, L., Abeele, V.V., 2012. Splash Controllers: Game Controllers Involving the Uncareful Manipulation of Water, in: Proceedings of the Sixth International Conference on Tangible, Embedded and Embodied Interaction, TEl '12. ACM, New York, NY, USA, pp. 183-186.

Howes, D., 2005. Empire of the Senses: The Sensual Culture Reader. Bloomsbury Academic.

Paley, V.G., 2009. A child's work: The importance of fantasy play. University of Chicago Press. 
Parés, N., Durany, J., Carreras, A., 2005. Massive Flux Design for an Interactive Water Installation: Water Games, in: Proceedings of the 2005 ACM SIGCHI International Conference on Advances in Computer Entertainment Technology, ACE '05. ACM, New York, NY, USA, pp. 266-269.

Plowman, L., Stephen, C., McPake, J., 2010. Growing Up With Technology: Young Children Learning in a Digital World. Routledge.
Raffe, W.L., Tamassia, M., Zambetta, F., Li, X., Pell, S.J., Mueller, F. "Floyd," 2015. PlayerComputer Interaction Features for Designing Digital Play Experiences Across Six Degrees of Water Contact, in: Proceedings of the 2015 Annual Symposium on Computer-Human Interaction in Play, CHI PLAY '15. ACM, New York, NY, USA, pp. 295-305. 